\title{
Papillary neoplasias of the biliary tract
}

\section{Neoplasias papiliferas do trato biliar}

\author{
Vivian Resende, tCBC-MG'; João Paulo lemos da Silveira Santos'; Rodrigo Vieira Gomes'; Paula Vieira Teixeira Vidigal²; \\ Moisés Salgado Pedrosa²
}

A B S T R A C T

\begin{abstract}
The authors conducted a revisional study of intraepithelial papillary lesions of the bile ducts, characterized by being a kind of rare, intraductal growing cholangiocarcinoma. Articles published in the last 10 years were reviewed. The authors considered that the adenoma-carcinoma development is an important feature to warrant prophylactic measures through excisions. The histological type and biomolecular behavior may have relevance in the postoperative course of such lesions, which have a better prognosis when compared with other histological types.
\end{abstract}

Key words: Neoplasms. Mucins. Common bile duct. Ampulla of Vater. Gallbladder.

\section{INTRODUCTION}

Intraductal papillary mucinous neoplasms (IPMN) are encompass a wide spectrum of lesions that range from cystic epithelial lesions to those with complex papillary architecture associated with invasive adenocarcinoma. These lesions were first described in the pancreas ${ }^{1,2}$, however, these neoplasms have been expanding to intra and extrahepatic bile ducts ${ }^{3-12}$, the ampullary region ${ }^{13}$ and, more recently, the gallbladder ${ }^{14,15}$.

Nonstandard names of IPMN are often found in the literature, from adenomas to papillary carcinoma, papillomatosis, in situ carcinoma and cholangiocarcinoma of papillary or polypoid type, among others $3-12,16-19$. Nevertheless, there is already a tendency to establish a consensus standardization and classification of such lesions ${ }^{13,14,20-22}$.

The hypothesis of the adenoma-carcinoma development of these lesions has been considered ${ }^{13,14,23-}$ 27. From a therapeutic point of view, this concept is important, especially because if diagnosed at an early stage of malignancy, they generally have a good prognosis $^{28-31}$.

Given the importance given to the study of IPMN in recent years, the objective of this work is to make a literature review on IPMN of the bile ducts, of the ampullary region and of the gallbladder, contributing to elucidate issues on the classification of this disease and better understand it.

\section{METHODS}

Having as source the PubMed database, we reviewed articles published in the last 10 years, having selected 45 , with emphasis on those published in the years 2008 to 2012, using the following keywords: "biliary tract", "ampulla", "papillary", "mucinous", "neoplasia".

\section{LITERATURE REVIEW}

The recognition of pancreatic IPMN led to the understanding of pre-invasive lesions of the biliary tract, which, in analogy to the pancreas, received the designation of biliary tract IPMN 3-12. These lesions have been described in the intra and extrahepatic biliary ducts $^{3,12}$, in the region of the ampulla ${ }^{13}$ and in the gallbladder 14,15 ; the tubular pre-invasive neoplasms, papillary and villous, including papillomatosis, were included in this category. In the WHO (World Health Organization) classification of 2010, the term was unified for IPN (Intraductal Papillary Neoplasm). It was suggested that the mucin term be removed, the production of such substance being less frequent in the bile duct ${ }^{14}$.

\section{ducts (BT-IPN)}

Intraductal papillary neoplasm of the bile

The mucin-producer IPN of the bile duct has been recognized apart from other neoplasms ${ }^{3-12}$; It represents the

1. Department of Surgery; Post-Graduate Program in Sciences Applied to Surgery and Ophthalmology, Faculty of Medicine, Federal University of Minas Gerais, Belo Horizonte, Minas Gerais State - MG, Brazil; 2. Department of Pathology, Faculty of Medicine, Federal University of Minas Gerais. 
biliary intraductal counterpart of the papillary mucinous neoplasms of the pancreas (PMNP). This disease category has had several different names, including intraductal papillary neoplasm of the liver, mucin hypersecretory papillomatosis, mucin hypersecretory cholangiocarcinoma, mucin-producing cholangiocarcinoma and mucin-producing bile duct tumor ${ }^{3-12,16-19}$. When intrahepatic, it differs from the biliary cystic mucinous neoplasm (CMN) by not presenting ovarian-type stromal and communicating with the bile ducts 32,33 .

The malignant neoplasm of the bile ducts is categorized as a type of intrahepatic cholangiocarcinoma (IHCC) of intraductal growth, relatively rare, constituting $3-9 \%$ of cholangiocarcinomas ${ }^{33}$. It can be successfully resected and present a more favorable prognosis when compared with other types of infiltrating cholangiocarcinomas of periductal infiltrative pattern, which generally have low resectability and unfavorable prognosis ${ }^{34}$, unlike the bile mucinous cystic neoplasm, which is usually confined to a closed cyst ${ }^{10,12,32}$. The BTIPN has the potential to spread along the mucosal surface of the biliary tract and, therefore, should be widely resected.
The papillary cancer of the bile ducts is characterized by the presence of numerous papillary lesions consisting of epithelial cells that surround a slender shaft anchored in connective fibrous tissue in the lamina propria9,2023,33 (Figures 1A and B). At histopathology, tumors can present a transition from adenoma to adenocarcinoma, which often coexist, deeming the adenoma-carcinoma sequence presumable ${ }^{23-27}$. As for the immunohistochemical study, it has been observed that the intrahepatic cholangiocarcinoma with intraductal growth showed expression of MUC2, the intestinal-type mucin, superior to other intrahepatic cholangiocarcinomas. Conversely, other types of IHCC showed expression of MUC1, the membrane-bound mucin, superior to those of intraductal growth $\mathrm{IHCC}^{33,35}$.

Bile ducts neoplasias produce mucin especially when they contains foci of mucinous elements. The tumors are soft and friable and tend to spread along the mucosal surface ${ }^{36,37}$. The excess of viscous mucin and detached tumors fragments can cause intermittent biliary obstruction and symptoms that include abdominal pain, jaundice, and fever ${ }^{15,32,36,37}$. The intermittent symptoms are characteristic of BT-IPN and are uncommon in other bile duct tumors.

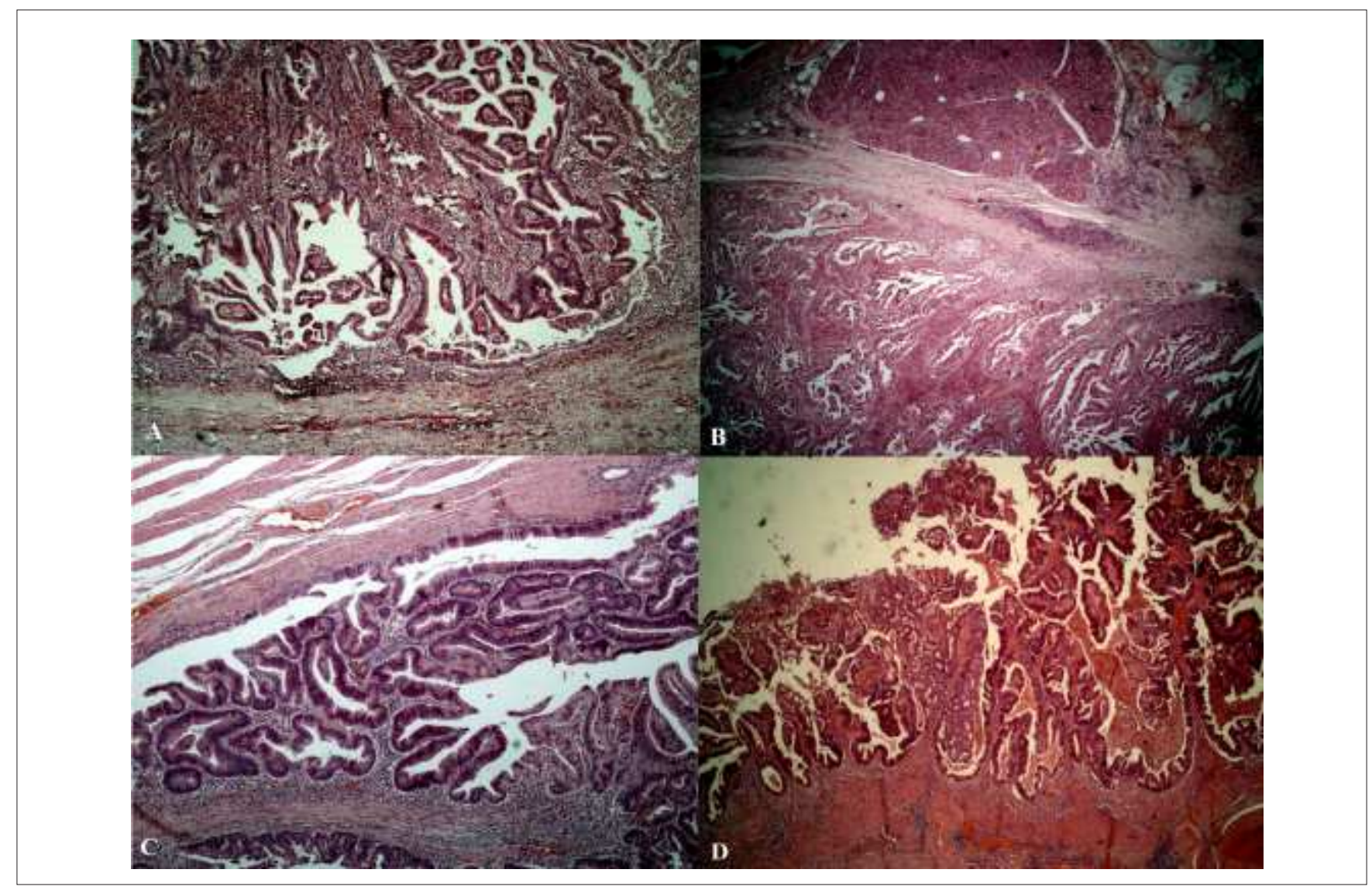

Figure 1 - Photomicrographs of papillary neoplasms with exophytic growth. A) Intraductal papillary neoplasm of the intrahepatic bile ducts (HE, 100X); B) Intraductal papillary neoplasm of the distal common bile duct (HE, 50X); C) Papilotubular intra-ampullary neoplasia of the hepatopancreatic papilla (HE, 100X); and D) Cholecystic intraepithelial papillary neoplasia of the gallbladder (HE, X100). 
The main features of an accurate diagnosis of BT-IPN are: the detection of mucobilia; the enlarged pattern of the bile ducts; shape, contrast and glucose metabolism of the wall nodule. Upstream dilation of the bile ducts is frequently observed in BT-IPN as in other types of IHCC. Moreover, there has often been seen a downstream expansion of the bile duct or of a part of the bile duct containing mucin producing tumors, due to the excessive mucin discharge or compression of the primary tumor. Even when the expansive lesion is not detectable by imaging exams, a tumor may be present in the dilated portion of the bile ducts. In addition, the wall nodule with reinforcement at ultrasound, computed tomography and magnetic resonance may be a sign of malignancy ${ }^{32}$. The increase in tumor glucose metabolism is also considered a sign of malignancy ${ }^{32}$

The differential diagnosis of BT-IPN includes cystic mucinous biliary neoplasm, intrahepatic cholangiocarcinoma of the infiltrating type in choledochal cysts and recurrent pyogenic cholangitis, with stones in the bile duct ${ }^{32,36}$. The intrahepatic cholangiocarcinoma with mass formation usually manifests as nodules. It can be easily differentiated from BT-IPN by imaging modalities including computed tomography and magnetic resonance ${ }^{32}$. Despite the malignant BT-IPN with parenchymal invasion sometimes look like a nodular mass, dilatation of the bile ducts downstream due to mucin secreted by BT-IPN may provide a clue to diagnosis. Recurrent pyogenic cholangitis with bile duct stones causes intermittent, incomplete biliary obstruction, intraluminal mass or filling defects similar to those observed for BT IPN ${ }^{36}$. The mucin plugs and BT-IPN fragments can be confused with bile duct stones, so it can be difficult to differentiate recurrent pyogenic cholangitis and bile duct calculi from BT-IPN based solely on image analysis. The endoscopic cholangiography or cholangioscopy may be necessary to demonstrate the presence of mucin plugs.

The important points for the accurate diagnosis of BT-IPN include the detection of mucobilia, the distribution of enlarged bile ducts, the shape, the contrast and the glucose metabolism of the wall nodule. Understanding the strengths and limitations of each modality is important to improve confidence and accuracy in the diagnosis and treatment of BT-IPN. In addition, a good understanding of the relationship between BT-IPN and pancreatic IPN is useful for understanding BT-IPN.

\section{Ampullary region neoplasms}

Although duodenal adenomas involving the papilla of Vater (surface of the duodenal ampulla) have already been well documented as the intestinal type or sporadic type adenomas (related with familial adenomatous poliposis - FAP) ${ }^{38-41}$, the data on those that arise specifically in inside the papilla are still very limited. Ohike et al. documented the morphological, immunohistochemical spectrum and clinical characteristics of 82 pre-invasive neoplastic lesions of the intra-ampullary region, in addition to invasive carcinomas of these types of lesions ${ }^{13}$. They proposed the descriptive term intra-ampullary papilotubular neoplasia (IAPN) for this lesions group until their nature is best understood.

The formation of intra-epithelial neoplasms analyzed in the study of Ohike et al. was similar to that of the pancreas IPMN and bile IPN ${ }^{1-12}$, which allowed their classification in parallel to these two categories $^{13}$. Similar to what happens in the neighboring places, these tumors are characterized by exophytic growth (papillary, tubular or papilotubular), with intestinal or gastric / pancreaticobiliary cell line and dysplastic change spectrum (adenoma-carcinoma sequence). So far, they have been classified as conventional ampullary adenocarcinomas or listed as adenomas of the duodenum, which may involve the surface of the duodenal papilla of Vater. However, it is believed that they should be differentiated from the previous ones, since, as is widely accepted, invasive NIPM carcinomas have different characteristics, including different biology and clinical behavior. In addition, the internal aspect of the ampulla, which is a transition region with several different morphometric characteristics, confer specific properties for these tumors ${ }^{13,30}$

Only a small percentage of IAPN exhibits the characteristics of pancreatic IPMN. The descriptor "mucinous" nomenclature was recently removed from the biliary neoplasms ${ }^{13}$. The papilotubular intra-ampullary neoplasias often produce only a minimal amount of mucin, in contrast to pancreatic NIPM, characterized by the usual profuse production of mucin.

Papilotubular intra-ampullary neoplasms were relatively rare in the study of Ohike et al. ${ }^{30}$, constituting $33 \%$ of the ampullary primary tumors and $5.5 \%$ of pancreatoduodenectomies / ampullectomies for the treatment of neoplasms. Only a third of cases of invasive carcinoma in the ampulla was associated with a IAPN component. This percentage is higher than in the pancreas, in which IPMN has been implicated in $10-22 \%$ of invasive carcinomas, and in the gallbladder, with a rate of $10 \%$ of invasive neoplasms ${ }^{14}$.

The mean age, 64 years old at diagnosis, is similar to that of patients with other cancers of the periampullary region, as in conventional carcinomas of the ampullary region, which occur predominantly in males ${ }^{13}$. The mean tumor size is also similar to the carcinomas resected in pancreatoduodenectomies ${ }^{28-31}$.

By definition, most IAPN macroscopically display a small exophytic growth on the surface of the duodenal papilla of Vater, and sometimes form a bulge in the lumen of the duodenal mucosa due to underlying proliferative process that fills the intra-ampullary lumen. The duodenal opening of the ampulla is generally ample, irregular and sometimes ulcerated. In histological sections of the papilla, papilotubular intra-ampullary neoplasms are characterized by exophytic polypoid lesions (Figure 1C) that fill the 
ampullary cavity or the intra-ampullary terminal portion of both the common bile duct and the pancreatic duct ${ }^{13}$.

From the microscopic stand point, there is a varying degree of papillary, tubular and mixed configuration. More than half of cases show a substantial mixture of these two growth patterns. The frequency of the mixed pattern may be partially attributable to the complexity of the ampullary mucosa, which contains numerous tributary glands, providing a tubular architecture for the process when involved by the pagetoid spread of IAPN cells. The meaning of the growth patterns requires further analysis, as the incidence and the amount of high-grade dysplasia tends to be higher in cases with papillary configuration, despite not having correlation with the incidence of invasion or prognosis $^{28,30}$.

Papilotubular intra-ampullary neoplasms exhibit a spectrum of neoplastic transformation (dysplasia) ${ }^{10}$. Over $80 \%$ of cases display a mixture of low and high grade dysplastic foci within the same lesion. The overall incidence of high-grade dysplasia is high, being absent in only a small minority ( $6 \%$ of cases). The existence and the amount of high-grade dysplasia may be higher in invasive carcinoma, and these may have a more aggressive behavior. However, this association did not reach statistical significance in the study of Ohike et al. ${ }^{30}$. The high incidence of high-grade dysplasia is intriguing, especially considering that these lesions are detected in relatively early stage. This suggests that, once started the neoplastic transformation in the epithelium of the ampulla, it can progress rapidly. This can be attributed to some inherent vulnerability factor of the mucosa or to its exposure to pancreatic, biliary and duodenal secretions.

Like their counterparts in the pancreas and biliary tract, the papilotubular intra-ampullary neoplasms exhibit a spectrum of cell lines that remember those found in different compartments of the gastrointestinal tract. A mixture of these cell lines coexist in about half the cases, which can be attributed to the nature of being located in the ampullary transition zone. This high incidence of mixed lineage also distinguishes IAPN from conventional types of intestinal adenomas that occur on the surface of the duodenal papilla, which are uniformly of intestinal type often exhibit different molecular events ${ }^{13,30}$.

\section{Neoplasms of the gallbladder (CIPN)}

The gallbladder lesions were included by Adsay et al., who defined parameters and proposed the name cholecystic intraepithelial papillary neoplasia (CIPN) with standardization similar to the pancreas ${ }^{14}$. These authors selected cases in a database, based on the following keywords: "gallbladder polyp", "adenoma", "cancer", "papillary". They also added 606 cases of invasive carcinoma, including initial carcinoma, which were analyzed to determine the frequency of lesions. They selected for CIPN cases with intramucosal exophytic lesions (papillary or polypoid) in the gallbladder (Figure 1D), which measured e" $1 \mathrm{~cm}$ and consisted of pre-invasive (dysplastic) neoplastic cells, forming a compact lesion distinct from the adjacent mucosa. The use of the e" $1 \mathrm{~cm}$ criteria was based on the widely employed indication of cholecystectomy in patients with polypoid lesions in the gallbladder detected in imaging studies ${ }^{42}$. There are studies reporting that lesions smaller than $1 \mathrm{~cm}$ rarely cause harm to the patient and should not be removed unless they cause symptoms ${ }^{42,43}$.

In their study, Adsay et al. found invasive carcinoma in CIPN ${ }^{14}$. Papilotubular intra-ampullary neoplasia was identified in $6.4 \%$ of cases of cancer of the gallbladder and most of them (87\%) were pancreaticobiliary-type adenocarcinoma. In those cases of association with invasive carcinoma, they were characterized by predominance of a papilotubular growth pattern (85\%), base cell line of biliary type $(69 \%)$ and extensive high-grade dysplasia (71\%) in the noninvasive component.

Patients with noninvasive carcinoma had survival at one, three and five years of $90 \%, 90 \%$ and $78 \%$, and $69 \%, 60 \%$ and $60 \%$, respectively, when associated with invasive disease. Even patients with CIPN (invasive disease) seem to have had a better prognosis, whose median survival was equal to 35 months $^{14}$, and nine months in patients with adenocarcinoma of the gallbladder ${ }^{44,45}$. However, Adsay et al. made no reference to the type of surgical or chemotherapeutic treatment used ${ }^{14}$, which could be a confounding factor in relation to prognosis, which was assigned only to histomorphological factors. Being a multicenter study, it could involve different approaches in relation to surgical and chemotherapeutic approach.

\section{FINAL CONSIDERATIONS}

A better understanding of mucinous papillary lesions of the biliary tract is of utmost importance. The adenoma-carcinoma development is an important feature in the adoption of preventive measures through excisions. The histological type and biomolecular behavior of these lesions are relevant in the postoperative evolution of conditions that generally have a better prognosis. 


\section{R E S U M O}

Os autores fizeram um estudo revisional sobre as lesões intraepiteliais papiliferas em ductos biliares, caracterizadas por serem um tipo de colangiocarcinoma raro, de crescimento intraductal. Foram revisados os artigos publicados nos últimos 10 anos. Os autores consideraram que a evolução adenoma-carcinoma é uma característica importante para se adotar medidas profiláticas por meio de ressecções. O tipo histológico e comportamento biomolecular podem ter relevância na evolução pós-operatória destas afecções que apresentam melhor prognóstico quando comparadas aos outros tipos histológicos.

Descritores: Neoplasias. Mucinas. Ducto biliar. Ampola de Vater. Vesícula biliar.

\section{REFERENCE}

1. Tanno S, Nakano $Y$, Nishikawa T, Nakamura K, Sasajima J, Minoguchi $M$, et al. Natural history of branch duct intraductal papillary-mucinous neoplasms of the pancreas without mural nodules: long-term follow-up results. Gut 2008;57(3):339-43.

2. Ardengh JC, Goldman SM, Lima-Filho ER. Papel atual dos métodos de imagem no diagnóstico das neoplasias císticas e sólidas do pâncreas. Rev Col Bras Cir. 2011:38(2):133-8

3. Zen $Y$, Fujii $T$, Itatsu $K$, Nakamura $K$, Minato $H$, Kasashima $S$, et al Biliary papillary tumors share pathological features with intraductal papillary mucinous neoplasm of the pancreas. Hepatology. 2006:44(5):1333-43

4. Yamashita Y, Fukuzawa K, Taketomi A, Aishima S, Yoshizumi T, Uchiyama $\mathrm{H}$, et al. Mucin-hypersecreting bile duct neoplasm characterized by clinicopathological resemblance to intraductal papillary mucinous neoplasm (IPMN) of the pancreas. World J Surg Oncol. 2007:5:98.

5. Nakanuma Y. A novel approach to biliary tract pathology based on similarities to pancreatic counterparts: is the biliary tract an incomplete pancreas? Pathol Int. 2010;60(6):419-29.

6. Rocha FG, Lee H, Katabi N, DeMatteo RP, Fong Y, D'Angelica MI, et al. Intraductal papillary neoplasm of the bile duct: a biliary equivalent to intraductal papillary mucinous neoplasm of the pancreas? Hepatology. 2012;56(4):1352-60

7. Kloek JJ, van der Gaag NA, Erdogan D, Rauwns EA, Busch OR, Gouma DJ, et al. A comparative study of intraductal papillary neoplasia of the biliary tract and pancreas. Hum Pathol. 2011;42(6):824-32.

8. Simo KA, Mckillop IH, Ahrens WA, Martinie JB, lannitti DA, Sindram D. Invasive biliary mucinous cystic neoplasm: a review. HPB 2012;14(11):725-40

9. Barton JG, Barrett DA, Maricevich MA, Schnelldorfer T, Wood CM, Smyrk TC, et al. Intraductal papillary mucinous neoplasm of the biliary tract: a real disease? HPB. 2009;11(8):684-91.

10. Zen $Y$, Fujii $T$, Itatsu K, Nakamura K, Konishi F, Masuda $S$, et al. Biliary cystic tumors with bile duct communication: a cystic variant of intraductal papillary neoplasm of the bile duct. Mod Pathol. 2006;19(9):1243-54

11. Yaman B, Nart D, Yilmaz F, Coker A, Zeytunlu M, Kilic M. Biliary intraductal papillary mucinous neoplasia: three case reports. Virchows Arch. 2009;454(5):589-94

12. Nahime $C B$, Lima Junior JA, Farah JFM, Bonadiman A, Herman $P$, Nacif MS. Qual o seu diagnóstico? Radiol Bras. 2011;44(3): IX-XI.

13. Ohike N, Kim GE, Tajiri T, Krasinskas A, Basturk O, Coban I, et al Intra-ampullary papillary-tubular neoplasm (IAPN): characterization of tumoral intraepithelial neoplasia occurring within the ampulla: A clinicopathologic analysis of 82 cases. Am J Surg Pathol. 2010;34(12):1731-48

14. Adsay V, Jang KT, Roa JC, Dursun N, Ohike N, Bagci $P$, et al. Intracholecystic papillary-tubular neoplasms (ICPN) of the gallbladder (neoplastic polyps, adenomas, and papillary neoplasms that are $\mathrm{e}^{\prime \prime} 1.0 \mathrm{~cm}$ ): clinicopathologic and immunohistochemical analysis of 123 cases. Am J Surg Pathol. 2012;36(9):1279-301.
15. Resende V, Roda R, Pedrosa MS. Gallbladder papillary neoplasia associated with intrahepatic carcinoma and pancreaticobiliary malformation. Gastroenterol Res. 2012;5(6):245-8.

16. Jiang L, Yan LN, Jiang LS, Li FY, Ye H, Li N, et al. Biliary papillomatosis: analysis of 18 cases. Chin Med J. 2008;121(24):2610-2.

17. Kosemehmetoglu K, Akpinar E, Sokmensuer C, Hamaloglu E. Papillary carcinoma with diffuse papillomatosis of gallbladder and cystic duct. Ann Diagn Pathol. 2011;15(2):140-4.

18. Kliment M, Urban O, Straka M, Kudelka L, Fojtik P, Falt P. Papillomatosis of the extrahepatic bile ducts and gallbladder diagnosed by endoscopic ultrasound (EUS) and endoscopic retrograde cholangiopancreatography (ERCP). Endoscopy. 2011;43 Suppl 2 UCTN:E321-2.

19. Chung JW, Kim MH, Choi EK, Lee SS, Seo DW, Lee SK. Mucinhypersecreting papillomatosis of the gallbladder. Gastrointest Endosc. 2006:64(3):435-6.

20. Albores-Saavedra J, Murakata L, Krueger JE, Henson DE. Noninvasive and minimally invasive papillary carcinomas of the extrahepatic bile ducts. Cancer. 2000;89(3):508-15.

21. Tanaka M, Fernández-del Castilho C, Adsay V, Chari S, Falconi M, Jang JY, et al. International consensus guideline 2012 for the management of IPMN and MCN of the pancreas. Pancreatology. 2012;12(3):183-97

22. Yamaguchi H, Shimizu M, Ban S, Koyama I, Hatori T, Fujita I, et al Intraductal tubulopapillary neoplasms of the pancreas distinct from pancreatic intraepithelial neoplasia and intraductal papillary mucinous neoplasms. Am J Surg Pathol. 2009;33(8):1164-72.

23. Albores-Saavedra J, Chablé-Montero F, González-Romo MA, Ramírez Jaramillo M, Henson DE. Adenomas of the gallbladder Morphologic features, expression of gastric and intestinal mucins, and incidence of high-grade dysplasia/carcinoma in situ and invasive carcinoma. Hum Pathol. 2012;43(9):1506-13

24. Tsuchida A, Itoi T, Aoki T, Koyanagi Y. Carcinogenic process in gallbladder mucosa with pacreaticobiliary maljunction (review). Oncol Rep. 2003;10(6):1693-9.

25. Okada T, Sasaki F, Honda S, Matsuno Y, Kubota K, Todo S Hyperplastic polyp of the gallbladder associated with pancreaticobiliary maljunction in a 9-year-old girl. Pediatr Surg Int 2009;25(11):999-1002

26. Kasuya K, Nagakawa Y, Matsudo T, Ozawa T, Tsuchida A, Aoki T, et al. p53 gene mutation and p53 protein overexpression in a patient with simultaneous double cancer of the gallbladder and bile duct associated with pancreaticobiliary maljunction. J Hepatobiliary Pancreat Surg. 2009;16(3):376-81

27. Adsay NV. Neoplastic precursors of the gallbladder and extrahepatic biliary system. Gastroenterol Clin North Am. 2007;36(4):889- 900, vii.

28. Albores-Saavedra J, Schwartz AM, Batich K, Henson DE. Cancers of the ampulla of vater: demographics, morphology, and survival based on 5,625 cases from the SEER program. J Surg Oncol. 2009;100(7):598-605.

29. Sommerville CA, Limongelli P, Pai M, Ahmad R, Stamp G, Habib $N A$, et al. Survival analysis after pancreatic resection for ampullary and pancreatic head carcinoma: an analysis of clinicopathological factors. J Surg Oncol. 2009;100(8):651-6. 
30. Ohike N, Coban I, Kim GE, Basturk O, Tajiri T, Krasinskas A, et al. Tumor budding as a strong prognostic indicator in invasive ampullary adenocarcinomas. Am J Surg Pathol. 2010;34(10):141724. Erratum in: Am J Surg Pathol. 2010;34(12):1892.

31. Neoptolemos JP, Moore MJ, Cox TF, Valle JW, Palmer DH, McDonald AC, et al. Effect of adjuvant chemotherapy with fluorouracil plus folinic acid or gemcitabine vs observation on survival in patients with resected periampullary adenocarcinoma: The ESPAC -3 periampullary cancer randomized trial. JAMA. 2012;308(2):147-56. Erratum in: JAMA. 2012;308(18):1861.

32. Takanami K, Yamada T, Tsuda M, Takase K, Ishida K, Nakamura $Y$, et al. Intraductal papillary mucininous neoplasm of the bile ducts: multimodality assessment with pathologic correlation. Abdom Imaging. 2011;36(4):447-56.

33. Ohtsuka M, Kimura F, Shimizu H, Yoshidome H, Kato A, Yoshitomi $H$, et al. Similarities and differences between intraductal papillary tumors of the bile duct with and without macroscopically visible mucin secretion. Am J Surg Pathol. 2011;35(4):512-21.

34. Patel T. Cholangiocarcinoma-controversies and challenges. Nat Rev Gastroenterol Hepatol. 2011:8(4):189-200.

35. Mall AS, Tyler MG, Ho SB, Krige JE, Kahn D, Spearman W, et al. The expression of MUC mucin in cholangiocarcinoma. Pathol Res Pract. 2010;206(12):805-9.

36. Tsuchida K, Yamagata M, Saifuku Y, Ichikawa D, Kanke K Murohisa T, et al. Successful endoscopic procedures for intraductal papillary neoplasm of the bile duct: a case report. World J Gastroenterol. 2010;16(7):909-13.

37. Sohn WJ, Jo S. A huge intraductal papillary mucinous carcinoma of the bile duct treated by right trisectionectomy with caudate lobectomy. World J Surg Oncol. 2009;7:93.

38. Schneider AR, Seifert H, Trojan J, Stein J, Hoepffner NM. Frequency of colorectal polyps in patients with sporadic adenomas or adenocarcinomas of the papilla of vater-an age-matched, controlled study. Z Gastroenterol. 2005;43(10):1123-7.

39. Hartenfels IM, Dukat A, Burg J, Hansen M, Jung M. Adenomas of Vater's ampulla and of the duodenum. Presentation of diagnosis and therapy by endoscopic interventional and surgical methods. Chirurg. 2002;73(3):235-40.

40. Bal A, Joshi K, Vaiphei K, Wig JD. Primary duodenal neoplasms: a retrospective clinico-pathological analysis. World J Gastroenterol. 2007;13(7):1108-11.

41. Cavallini M, Cavaniglia D, Felicioni F, Vitale V, Pilozzi E, Ziparo V. Large periampullary villous tumor of the duodenum. J Hepatobiliary Pancreat Surg. 2007;14(5):526-8.

42. Myers RP, Shaffer EA, Beck P. Gallbladder polyps: epidemiology, natural history and managment. Can J Gastroenterol. 2002;16(3):187-94.

43. Gourgiotis S, Kocher HM, Solaini L, Yarollahi A, Tsiambas E, Salemis NS. Gallbladder cancer. Am J Surg. 2008;196(2):252-64.

44. Shirai Y, Wakai T, Sakata J, Hatakeyama K. Regional lymphadenectomy for gallbladder cancer: rational extent, technical details, and patient outcomes. World J Gastroenterol. 2012;18(22):2775-83.

45. Stinton LM, Shaffer EA. Epidemiology of gallbladder disease: cholelithiasis and cancer. Gut Liver. 2012;6(2):172-87.

Received 15/10/2013

Accepted for publication 20/01/2014

Conflict of interest: none.

Source of funding: none.

\section{Mailing address:}

Vivian Resende

E-mail: vivianresende.ufmg@gmail.com 